\title{
Analysis of alkali ultrasonication pretreatment in bioethanol production from cotton gin trash using FT-IR spectroscopy and principal component analysis
}

\author{
Jersson Plácido* and Sergio Capareda
}

\begin{abstract}
Background: Cotton gin trash (CGT) is a lignocellulosic residue that can be used in the production of cellulosic ethanol. In a previous research, the sequential use of ultrasonication, liquid hot water, and ligninolytic enzymes was selected as pretreatment for the production of ethanol from CGT. However, an increment in the ethanol production is necessary. To accomplish that, this research evaluated the effect of pretreating CGT using alkaline ultrasonication before a liquid hot water and ligninolytic enzymes pretreatments for ethanol production. Three $\mathrm{NaOH}$ concentrations $(5 \%, 10 \%$, and $15 \%)$ were employed for the alkaline ultrasonication. Additionally, this work is one of the first applications of Fourier transform infrared (FT-IR) spectrum and principal component analysis (PCA) as fast methodology to identify the differences in the biomass after different types of pretreatments.
\end{abstract}

Results: The three concentrations employed for the alkaline ultrasonication pretreatment produced ethanol yields and cellulose conversions higher than the experiment without $\mathrm{NaOH}$. Furthermore, 15\% $\mathrm{NaOH}$ concentration achieved twofold increment yield versus the treatment without $\mathrm{NaOH}$. The FT-IR spectrum confirmed modifications in the CGT structure in the different pretreatments. PCA was helpful to determine differences between the pretreated and un-pretreated biomass and to evaluate how the CGT structure changed after each treatment.

Conclusions: The combination of alkali ultrasonication hydrolysis, liquid hot water, and ligninolytic enzymes using $15 \%$ of $\mathrm{NaOH}$ improved $35 \%$ the ethanol yield compared with the original treatment. Additionally, we demonstrated the use of PCA to identify the modifications in the biomass structure after different types of pretreatments and conditions.

Keywords: Alkali-hydrolysis; Cotton gin trash; Ethanol production; FT-IR; Ligninolytic enzymes; Principal components analysis; Ultrasonication

\section{Background}

Cotton is one of the major crops grown in the world. In 2006 to 2007, the worldwide production was 24 million tons and it continues to increase by $2 \%$ each year [1]. The residues from cotton production are of two types: cotton plant trash (CPT) and cotton gin trash (CGT) [2]. CPT is the residue that stays in the field after the harvest of cotton; while CGT is the residue coming from the ginning process. CGT is composed of pieces of sticks, leaves, bolls,

\footnotetext{
* Correspondence: plac324@tamu.edu

Department of Biological and Agricultural Engineering, Texas A\&M University, Room 201 Scoates Hall, TAMU 2117, College Station, Texas 77841, USA
}

and soil cleaned from lint during ginning. In fact, $218 \mathrm{~kg}$ of cotton generates 68 to $91 \mathrm{~kg}$ of CGT [1]. Annually, the production of this waste in the USA is around 2.26 million tons [3].

The United States regulation requires by 2020 the production of 36 billion gallons of biofuels and from these, 21 billion should be produced from lignocellulosic materials or other new advanced fuels [4]. Agro-industrial waste (i.e., CGT) is one of the most significant sources of lignocellulosic materials, and bio-ethanol is one of the most essential bio-fuels produced from this kind of wastes. In general, bio-ethanol production from lignocellulosic 
material includes three principal steps: 1) pretreatment, 2) saccharification, and 3) fermentation. To produce bioethanol from agro-industrial feedstocks, different kinds of pretreatments have been investigated. These are generally divided into physical, physicochemical, chemical, and biological [5]. In CGT, the pretreatment principally used is physicochemical (steam explosion) followed by chemical (acid or basic hydrolysis) and biological (fungal or enzymatic) pretreatment [6,7]. Current biomass pretreatment process utilizes energy intense methodologies (high pressures and temperatures) and harsh chemical compounds.

To overcome the issues related with the traditional pretreatment process, new pretreatment strategies have been evaluated and developed. One of these strategies is the combination of ultrasonication, liquid hot water, and ligninolytic enzymes [8]. The ultrasonication and liquid hot water modified the lignin and cellulose structure; meanwhile, the ligninolytic enzymes treatment realized a detoxification and delignification process. This combination generated an ethanol yield of $30 \%$ and cellulose conversion of $23 \%$ [8]; however, both results need to be increased. Cellulose conversion and ethanol yield can be improved by modifying the pretreatment's conditions. Several works proved the efficiency of basic hydrolysis to decrease the lignin content in biomass [9]. Additionally, in sweet sorghum bagasse, the combination of alkaline hydrolysis simultaneously with ultrasonication augmented the final ethanol yield and cellulose conversion [10]. The use of ultrasonication and alkali-hydrolysis has not been tested in CGT; thus, the synergic effect of these technologies may raise delignification, cellulose conversion, and ethanol yield from CGT. The effect of these pretreatments over the CGT structure can be determined using compositional analysis [11] and/or the biomass' Fourier transform infrared (FT-IR) spectrum. In this moment, FT-IR is principally applied to study qualitatively the modifications in the structure and is not utilized for quantitative analysis. However, FT-IR is a fastest technique compared with the traditional compositional examination and can be used as a tool to identify qualitatively modification in biomass structure after different pretreatments. As a complementary tool to FT-IR spectroscopy, multivariate statistical techniques have been employed to identify the modifications in the FT-IR spectra and evaluate the difference between the different treatments. One of these multivariate methods is the principal component analysis (PCA); this technique reduces the dimensionality of the data by explaining the variance-covariance structure of a set of variables using few linear combinations of these variables. The use of PCA facilitates the visualization of the spectra changes and the identification of the most important features of the FT-IR spectra as the peak shifts and nonsymmetries [12]. The use of FT-IR coupled with PCA in pretreated and un-pretreated CGT has not been evaluated in any other research. In the future, this type of methodology can be applied in quality or process control, and if it is coupled with regression techniques, it can be useful to make quantitative evaluations of the biomass composition.

This research evaluated the application of alkali ultrasonication pretreatment as a methodology to increase the ethanol yield produced from CGT using the combination of ultrasonication, liquid hot water, and ligninolytic enzyme. Additionally, FT-IR and PCA were utilized as a tool to analyze the modifications in the biomass structure after pretreatment methodologies.

\section{Methods}

\section{Substrate}

The samples of CGT were obtained from the VariscoCourt Gin CO near College Station, in Brazos Valley County, Texas. The CGT samples were ground in a Wiley mill (Philadelphia, PA, USA) to achieve an average particle size of approximately $1 \mathrm{~mm}$ in diameter.

\section{Pretreatments}

The experiment followed the selected sequence of pretreatments such as ultrasonication, liquid hot water, and ligninolytic enzymes [8]. However, the ultrasonication step was modified to simultaneously perform a basic hydrolysis using different concentrations of $\mathrm{NaOH}$. Table 1 lists the experiments utilized in this paper. The experimental design was completely randomized with the $\mathrm{NaOH}$ concentration as factor with four levels $(15 \%, 10 \%, 5 \%$, and $0 \% \mathrm{w} / \mathrm{v}$ ) and a control of un-pretreated CGT. All the experiments were developed in three replicates using cellulose conversion and ethanol yield as response variables. The ultrasonication process employed a solution of $10 \%$ solids of CGT biomass and the corresponding $\mathrm{NaOH}$ concentration for $1 \mathrm{~h}$. The ultrasonicator (Hielscher Ultrasonic Processors, Ringwood, NJ, USA) was set at the highest value of amplitude (100\%) and cycle (1). After the alkali ultrasonication, the solution was neutralized and centrifuged at 5,000 rpm for $5 \mathrm{~min}$. The pelletized biomass was not washed before the hot water treatment, thus small quantities of $\mathrm{NaOH}$ are still present in the hot water treatment. The hot water pretreatment used Erlenmeyer flasks with $10 \%$ solution solids at $121^{\circ} \mathrm{C}, 15$ psi for $1 \mathrm{~h}$

\section{Table 1 Pretreatments evaluated in the experiment}

\begin{tabular}{ll}
\hline Pretreatments sequence & Abbreviation \\
\hline $\begin{array}{l}\text { Ultrasonication + liquid hot water }+ \\
\text { ligninolytic enzymes }\end{array}$ & $(\mathrm{U}+\mathrm{HW}+\mathrm{E})$ \\
$\begin{array}{l}\text { Ultrasonication/ } \mathrm{NaOH} 5 \%+\text { liquid hot water }+ \\
\text { ligninolytic enzymes }\end{array}$ & $(\mathrm{U}-\mathrm{NaOH} 5 \%+\mathrm{HW}+\mathrm{E})$ \\
$\begin{array}{l}\text { Ultrasonication/ } \mathrm{NaOH} 10 \%+\text { liquid hot water }+ \\
\text { ligninolytic enzymes }\end{array}$ & $(\mathrm{U}-\mathrm{NaOH} 10 \%+\mathrm{HW}+\mathrm{E})$ \\
$\begin{array}{l}\text { Ultrasonication/NaOH} 15 \%+\text { liquid hot water }+ \\
\text { ligninolytic enzymes }\end{array}$ & $(\mathrm{U}-\mathrm{NaOH} 15 \%+\mathrm{HW}+\mathrm{E})$ \\
\hline
\end{tabular}


in an autoclave. The ligninolytic enzymes pretreatment consists of the commercial laccase mediator system PrimaGreen $^{\oplus}$ EcoFade LT100 from GENENCOR International Inc. (Palo Alto, CA, USA). The enzymatic reactions were performed in 250-ml Erlenmeyer flasks with $50 \mathrm{ml}$ of phosphate buffer $25 \mathrm{mM} \mathrm{pH} \mathrm{6,} \mathrm{an} \mathrm{initial} \mathrm{enzyme} \mathrm{load}$ of $3 \mathrm{~g}$, with $10 \%$ solids of CGT at $30^{\circ} \mathrm{C}, 150 \mathrm{rpm}$ for 96 h (Innova, New Brunswick Scientific, NJ, USA).

\section{Saccharification process}

The saccharification process employed the combination of two types of commercial cellulases: Accellerase 1500 and Accellerase XY (GENENCOR, Palo Alto, CA, USA). The experiment had an initial enzyme loading of $0.3 \mathrm{ml} / \mathrm{g}$ of Accellerase $1,500+0.1 \mathrm{ml} / \mathrm{g}$ of Accellerase XY. The process utilized three replicates in 250-ml Erlenmeyer flasks with $50 \mathrm{ml}$ of a solution of $50-\mathrm{mM}$ sodium acetate buffer at $\mathrm{pH} 4.8$ for $96 \mathrm{~h}$ at $50^{\circ} \mathrm{C}$ and $125 \mathrm{rpm}$ in an incubator/shaker (Innova, New Brunswick Scientific, NJ, USA). Cellulose conversion was calculated by using the next equation: \% glucose conversion $=[(c \times V) / m] \times 100$ $\%$, where $c$ is the concentration $(\mathrm{g} / \mathrm{L})$ of sugars in the sample hydrolyzed, as determined by high performance liquid chromatography (HPLC), $V$ is the total volume (L) hydrolyzed, and $m$ is the initial weight (g) of glucose or xylose determined through the National Renewable Energy Laboratory (NREL) protocols. The statistical tests were performed in the software SAS system 9.3.

\section{Fermentation process}

Ethanol Red (Saccharomyces cerevisiae) provided by Fermentis (Lesaffre Yeast Corp., Milwaukee, WI, USA) was employed for the fermentation process. The activation of the strain was in $0.5 \mathrm{~g}$ of dry yeast in $10 \mathrm{~mL}$ of the inoculum broth. The composition of the inoculum broth had $0.2 \mathrm{~g}$ glucose, $0.05 \mathrm{~g}$ peptone, $0.03 \mathrm{~g}$ yeast extracts, $0.01 \mathrm{~g} \mathrm{KH}_{2} \mathrm{PO}_{4}$, and $0.005 \mathrm{~g} \mathrm{MgSO}_{4} \cdot 7 \mathrm{H}_{2} \mathrm{O}$. The inoculums were shaken at $200 \mathrm{rpm}$ in an incubator shaker at $38^{\circ} \mathrm{C}$ for 25 to $30 \mathrm{~min}$. The fermentation process was performed in 125-ml Erlenmeyer flasks with $50 \mathrm{ml}$ of the slurry supplemented with $0.3 \mathrm{~g}$ of yeast extract. The slurry was then incubated with $1 \mathrm{ml}$ of freshly activated dry yeast (Ethanol Red) and run for a period of $72 \mathrm{~h}$ at $32^{\circ} \mathrm{C}, \mathrm{pH} 4$, and $100 \mathrm{rpm}$. The ethanol yield was calculated from the ratio between the average produced ethanol and the theoretical ethanol production of $51.1 \mathrm{~g}$ of ethanol generated per $100 \mathrm{~g}$ of glucose in the biochemical conversion of the sugar. The response variable was the ethanol yield, and it was analyzed using the software SAS system 9.3 employing one-way ANOVA and the LSD test.

\section{High-performance liquid chromatography}

After each of the processes (saccharification and fermentation), the samples were centrifuged at 10,000 rpm for
$10 \mathrm{~min}$, and the supernatants were filtered through $0.45-\mu \mathrm{m}$ hydrophilic PTFE syringe filters (Millipore, Billerica, MA, USA). These samples were then analyzed for glucose, mannose, xylose, arabinose, galactose, and cellobiose concentration using HPLC (Waters 2690, Separations Module, Waters Corporation, Milford, MA, USA) equipped with an auto-sampler, Shodex SP 810 (Shodex, New York, NY, USA) packed column, and a refractive index (RI) detector. Each sample ran for $25 \mathrm{~min}$ at a flow rate of $1 \mathrm{ml} / \mathrm{min}, 60^{\circ} \mathrm{C}$ using HPLC water as mobile phase.

\section{Compositional analysis}

To determine the composition of the CGT biomass before and after the pretreatments, the analytical protocols developed at the NREL of the US Department of Energy were followed. This entailed the determination of (a) total solids in biomass and total dissolved solids in liquid process samples, (b) extractives in biomass, and (c) structural carbohydrates and lignin in biomass [11]; the past protocols were developed using dried biomass. FT-IR spectroscopy (Shimadzu, IR Affinity-1 with a MIRacle universal sampling accessory; Kyoto Prefecture, Japan) was used to evaluate the properties of the CGT with and without pretreatments. The infrared spectra collected range was 4,000 to $700 \mathrm{~cm}^{-1}$ with a resolution of $4 \mathrm{~cm}^{-1}$. The compounds were analyzed, and their wavenumbers are given in Table 2. The spectra examination was developed using PCA in the range between 800 and $1,800 \mathrm{~cm}^{-1}$. The PROC PRINCOMP statement of the SAS system 9.3 was employed for the PCA calculations using the correlation matrix of the data.

\section{Results and discussion}

\section{Cellulose conversion}

The effect of alkali ultrasonication employed two response variables, cellulose conversion and ethanol yield. Figure 1 shows the bar plot of the cellulose conversion for each pretreatment. The experiments with pretreatments evidence

\begin{tabular}{|c|c|c|}
\hline Compound & Functional group & Wave number $\left(\mathrm{cm}^{-1}\right)$ \\
\hline Cellulose & Beta-D-cellulose & 898 \\
\hline Cellulose & Intense polysaccharide & 1,$030 ; 1,050$ \\
\hline Cellulose & $\begin{array}{l}\text { C-O-C anti-symmetric } \\
\text { stretch (b-1,4 glycosyl) }\end{array}$ & 1,170 to 1,150 \\
\hline Cellulose & $\begin{array}{l}\text { Cellulose II and amorphous } \\
\text { cellulose strong broad band }\end{array}$ & 1,090 \\
\hline Lignin & $\begin{array}{l}\text { Phenolic } \mathrm{OH} \text { region and } \\
\text { aliphatic } \mathrm{CH} \text { stretch }\end{array}$ & 1,370 \\
\hline Lignin & $\begin{array}{l}\text { Aromatic skeletal vibration } \\
\text { and } \mathrm{CH} \text { deformation }\end{array}$ & 1,$514 ; 1,595$ \\
\hline Hemicellulose & Ester carbonyls, $\mathrm{C}=\mathrm{O}$ & 1,$240 ; 1,732$ \\
\hline
\end{tabular}




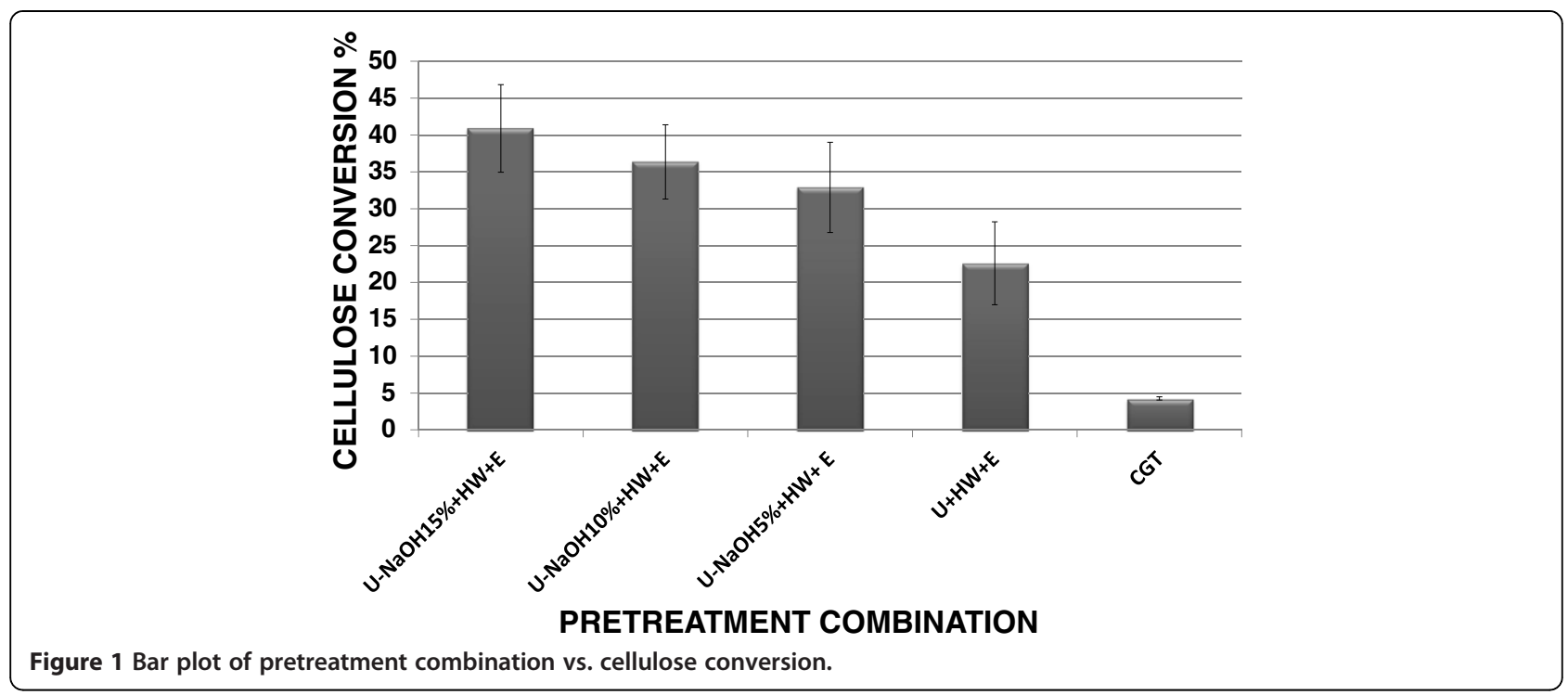

an increment between $16 \%$ and $35 \%$ in the cellulose conversion over the un-pretreated biomass. Additionally, the treatments with alkali ultrasonication revealed a cellulose conversion greater than the treatment with only ultrasonication; this increment fluctuated between $11 \%$ and $18 \%$. The statistical analysis (Table 3) indicates that statistically the alkali hydrolysis pretreatments are not different from each other. However, the treatments U-NaOH $15 \%+\mathrm{HW}$ $+\mathrm{E}$ and $\mathrm{U}-\mathrm{NaOH} 10 \%+\mathrm{HW}+\mathrm{E}$ were statistically different compared with the $\mathrm{U}+\mathrm{HW}+\mathrm{E}$. The $5 \%$ treatment did not get significant differences against the $\mathrm{U}+\mathrm{HW}$ + E. It indicates that $5 \%$ treatment increased the cellulose conversion similar to $\mathrm{U}-\mathrm{NaOH} 15 \%+\mathrm{HW}+\mathrm{E}$, but the increment is not enough to be different than the pretreatment without alkali hydrolysis. The U-NaOH $15 \%+$ HW + E's cellulose conversion (40\%) of CGT was larger than the microbial pretreatment (18\%) [13] and the sulfuric acid pretreatment [6] both over cotton stalks. Additionally, the cellulose conversion in this research is comparable with the achieved by steam explosion with a severity factor of $2(42 \%)$ in CGT [3]. Nevertheless, the $\mathrm{U}-\mathrm{NaOH} 15 \%+\mathrm{HW}+\mathrm{E}$ conversion is lower than the results accomplished in CGT with a severity factor of $4.68(66.88 \%)$ [3] and the steam explosion of CGT and recycled paper sludge (73.8\%) [7]. The $\mathrm{NaOH}$ hydrolysis has been evaluated in other cotton wastes as textile wastes [14] and cotton stalks [6]. In both wastes, the use of $\mathrm{NaOH}$ improved the cellulose conversion, similar to the results displayed in this study.

The cellulose conversion using alkali ultrasonication on CGT (40\%) was larger than the conversion found by Silverstein et al. [6] in cotton stalks (21\%) but it was lower than Kaur et al. [15] over cotton stalks (63\%) and Jeihanipour and Taherzadeh [14] in textiles wastes (99\%). The difference between CGT and textile wastes is associated with their composition. Textile wastes comprise small lignin content which allows an easy access to the cellulose. Alkali hydrolysis has been utilized in several types of biomass (sugarcane bagasse, sweet sorghum bagasse, corn stover, etc.) to reduce the lignin content [16]. This pretreatment is normally related with the removal of lignin because $\mathrm{NaOH}$ breaks the ester bonds cross-linkage in lignin and xylan [9]. This breaking augments the biomass porosity allowing an easier access of the enzymes to the cellulose. However, alkali hydrolysis normally does not produce considerable modification in the cellulose structure, and this type of modification is necessary to increase the cellulose conversion [6]. The

Table 3 LSD's test for the cellulose conversion and ethanol yield

\begin{tabular}{|c|c|c|c|c|c|}
\hline Pretreatment & LSD's statistic $^{\mathrm{a}}$ & Cellulose conversion & Pretreatment & LSD's statistic $^{1}$ & Ethanol yield \\
\hline $\mathrm{U}-\mathrm{NaOH} 15 \%+\mathrm{HW}+\mathrm{E}$ & A & $0.409 \pm 0.059$ & $\mathrm{U}-\mathrm{NaOH} 15 \%+\mathrm{HW}+\mathrm{E}$ & A & $0.639 \pm 0.139$ \\
\hline $\mathrm{U}-\mathrm{NaOH} 10 \%+\mathrm{HW}+\mathrm{E}$ & A & $0.363 \pm 0.050$ & $\mathrm{U}-\mathrm{NaOH} 10 \%+\mathrm{HW}+\mathrm{E}$ & $A B$ & $0.585 \pm 0.0563$ \\
\hline $\mathrm{U}-\mathrm{NaOH} 5 \%+\mathrm{HW}+\mathrm{E}$ & $A B$ & $0.329 \pm 0.061$ & $\mathrm{U}-\mathrm{NaOH} 5 \%+\mathrm{HW}+\mathrm{E}$ & B & $0.514 \pm 0.077$ \\
\hline$U+H W+E$ & B & $0.226 \pm 0.056$ & $U+H W+E$ & C & $0.28867 \pm 0.086$ \\
\hline CGT & C & $0.042 \pm 0.002$ & CGT & D & $0.08000 \pm 0.104$ \\
\hline
\end{tabular}

${ }^{\mathrm{a}}$ Means with the same letter are not significantly different from each other. 
combination of alkaline pretreatment and ultrasonication have been evaluated in sugarcane bagasse and rice straw. In sugarcane, alkali ultrasonication boosted the cellulose conversion approximately $50 \%$ against the unpretreated biomass and $40 \%$ versus the pretreatment without ultrasonication [17]. The difference between the pretreated and un-pretreated biomass coincides with the results of this research (Figure 1). In rice straw, the alkali ultrasonication exhibited cellulose conversion greater than the un-pretreated biomass and the alkali pretreatment; nevertheless, the difference between the alkali pretreatment and the alkali ultrasonication was small [18]. The cellulose conversion can be enhanced by different strategies such optimizing the severity of the liquid hot water pretreatment or improving the conditions of the ligninolytic enzymes and ultrasonication pretreatment (reaction time, temperatures, etc.).

\section{Ethanol yield}

The second variable analyzed for the pretreatments was the ethanol yield (Figure 2). This variable evidenced a clear difference (55\% to $20 \%$ ) between the pretreated biomass and the un-pretreated biomass. The ethanol yield produced by the alkali ultrasonication treatments increased compared with the $\mathrm{U}+\mathrm{HW}+\mathrm{E}$ treatment. It indicates a beneficial effect in the use of alkali hydrolysis with the ultrasonication pretreatment for the ethanol production. The greatest ethanol yield was obtained in the U-NaOH $15 \%+\mathrm{HW}+\mathrm{E}$ and $\mathrm{U}-\mathrm{NaOH} 10 \%+\mathrm{HW}$ + E pretreatments with $63 \%$ and $58 \%$, respectively. The statistical analysis of the experiment (Table 3) describes that $\mathrm{U}-\mathrm{NaOH} 15 \%+\mathrm{HW}+\mathrm{E}$ and $\mathrm{U}-\mathrm{NaOH} 10 \%+\mathrm{HW}$ + E were not statistically different. Meanwhile, all the alkaline hydrolysis treatments were different other than $U$ $+\mathrm{HW}+\mathrm{E}$.
The U-NaOH $15 \%+\mathrm{HW}+$ E's ethanol yield was higher than the yield reported by Shen and Agblevor [7] on a mix of CGT and recycled paper sludge (40\%). Additionally, our results are comparable with the ones described for CGT using steam explosion and a severity of 3.47 (58.1\%) [3]. However, the ethanol yield of this research exhibited low values compared with the yields described by Jeoh and Agblevor [3] and Agblevor et al. [19] in CGT with conversions around 78\% to 95\% [19]. The increment in the ethanol yield using $\mathrm{NaOH}$ and ultrasonication has been found in other feedstock such as hazelnut husks [10], cotton stalk [15], and sugar cane bagasse [10]. The ethanol yields produced in sugar cane bagasse $(81 \%)$ and hazelnut husks $(76.7 \%)$ were higher than the $\mathrm{U}-\mathrm{NaOH} 15 \%+\mathrm{HW}+\mathrm{E}$ pretreatment $(63 \%)$; meanwhile, the alkali-ultrasonicated cotton stalk had an ethanol yield (41\%) [15] that is lower than the pretreatment combination selected in this research.

\section{Compositional analysis}

Table 4 illustrates the composition of the biomass at the end of the pretreatments. The principal differences were in the glucose and acid insoluble material. The use of alkali ultrasonication produced a decrease in the lignin content, and this was related with the concentration of $\mathrm{NaOH}$. The highest reduction occurred in the treatment with $15 \%$ of $\mathrm{NaOH}$; meanwhile, the $10 \%$ and $5 \%$ treatments exhibited similar values. In studies with sweet sorghum, the alkali ultrasonication reduced the lignin content $6 \%$ to $10 \%$ [10], which has a similar level as that found in CGT. The glucose percentage in alkali ultrasonication treatments increased in comparison with the untreated CGT and the $\mathrm{U}+\mathrm{HW}+\mathrm{E}$ treatment. Similar to the lignin percentage, the greatest change was in the $\mathrm{U}-\mathrm{NaOH} 15 \%+\mathrm{HW}+\mathrm{E}$ treatment. In this case, the

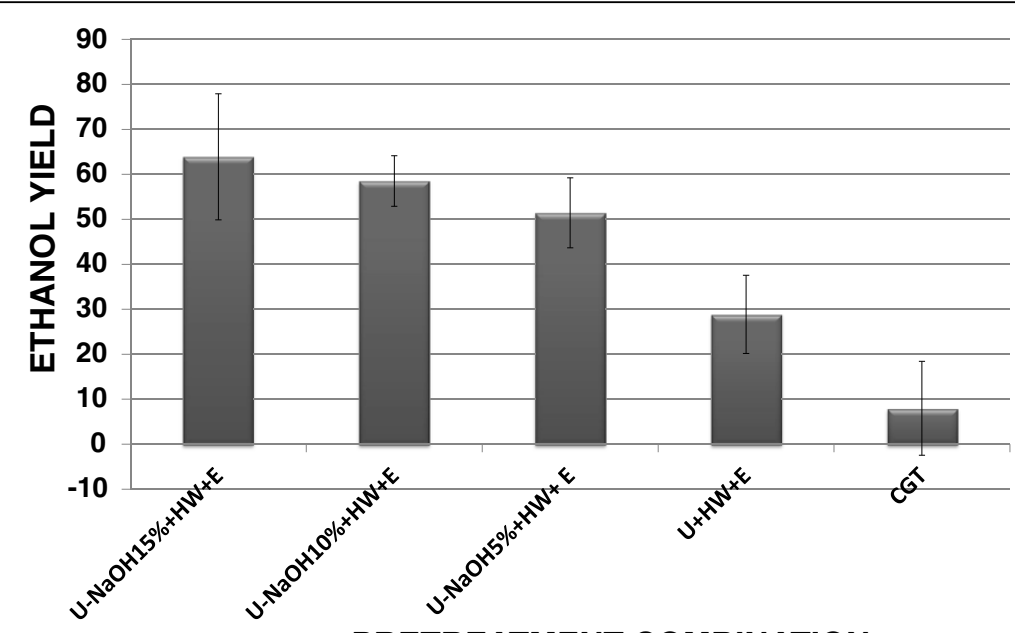

PRETREATMENT COMBINATION

Figure 2 Bar plot of pretreatment combination vs. ethanol yield. 
Table 4 Structural composition of untreated and pretreated cotton gin trash (CGT)

\begin{tabular}{|c|c|c|c|c|c|}
\hline Compound & CGT & $\mathrm{U}+\mathrm{HW}+\mathrm{E}$ & $\mathrm{U}-\mathrm{NaOH} 5 \%+\mathrm{HW}+\mathrm{E}$ & U-NaOH $10 \%+\mathrm{HW}+\mathrm{E}$ & $\mathrm{U}-\mathrm{NaOH} 15 \%+\mathrm{HW}+\mathrm{E}$ \\
\hline Water and ethanol extractives & 19.6 & 15.3 & 14.9 & 14.3 & 14.5 \\
\hline Acid insoluble material & 25.5 & 22.9 & 20.5 & 19.5 & 18.7 \\
\hline Arabinose & 1.5 & 1.2 & 1.3 & 1.4 & 1.9 \\
\hline Xylose & 5.7 & 5.4 & 5.3 & 5.1 & 5.2 \\
\hline Mannose & 1.1 & 1.3 & 1.1 & 1.3 & 1.3 \\
\hline Galactose & 1.7 & 1.6 & 1.3 & 1.4 & 1.2 \\
\hline Glucose & 24.9 & 29.8 & 31.3 & 33.1 & 35.5 \\
\hline Ash & 10.7 & 10.3 & 11.7 & 12.1 & 12.5 \\
\hline
\end{tabular}

increment was around 10\% compared with the original biomass and $6 \%$ versus the $\mathrm{U}+\mathrm{HW}+\mathrm{E}$ treatment. In this variable, the treatment with $10 \%$ showed a glucan content greater than the $5 \%$ treatment. The other sugars exhibited slightly diminutions compared with the untreated CGT and $\mathrm{U}+\mathrm{HW}+\mathrm{E}$ treatment. This type of small reductions in the hemicellulose components have been reported in barley straw [20] and sorghum [10]. The use of large concentrations of $\mathrm{NaOH}$ has been reported as a methodology to solubilize the hemicellulose components; however, this methodology has reaction times $(24 \mathrm{~h})$ greater than the alkali ultrasonication pretreatment $(1 \mathrm{~h})$. The short reaction time in the alkali ultrasonication avoided a larger hemicellulose solubilization.

FT-IR was performed in this study to monitor the composition changes in the CGT biomass according with the pretreatments employed. The analyzed peaks (Table 2) and new strong signals were followed in all the samples. Figure 3 shows the FT-IR spectra of the pretreatment sequence of $\mathrm{U}-\mathrm{NaOH} 15 \%+\mathrm{HW}+\mathrm{E}$. The addition of $\mathrm{NaOH}$ produced an increment in the signals at 800 to $900 \mathrm{~cm}^{-1}$ and 1,300 to $1,500 \mathrm{~cm}^{-1}$; the outstanding peak was the signal at $1,431 \mathrm{~cm}^{-1}$ followed by the 1,402 and $1,327 \mathrm{~cm}^{-1}$. These peaks are related with the presence of $\mathrm{NaOH}$ because they augmented depending of the $\mathrm{NaOH}$ concentration and were only observed in the pretreatments with alkali hydrolysis. These signals reduced through the pretreatments; in fact, after the laccase pretreatment and the enzymatic hydrolysis, these peaks were not seen. The reduction in the $\mathrm{NaOH}$ peaks indicates that this compound did not have considerable concentrations that could affect the saccharification and fermentation processes.

The absorbance in the cellulose's peaks (898, 1,030, $1,050,1,090$, and 1,170 to $1,150 \mathrm{~cm}^{-1}$ ) increased at the end of the four experiments. The highest increment in all the pretreatments was the $1,090 \mathrm{~cm}^{-1}$ peak followed by the signals at $898,1,030$, and $1,050 \mathrm{~cm}^{-1}$. U-NaOH $15 \%+\mathrm{HW}+\mathrm{E}$ (Figure 3 ) obtained the highest increment among the treatments in all the cellulose picks followed by $\mathrm{U}-\mathrm{NaOH} 10 \%+\mathrm{HW}+\mathrm{E}$ pretreatment. The absorbance in the cellulose's signal was increasing according to the pretreatments that were added, showing a synergic effect of the pretreatments over the cellulose

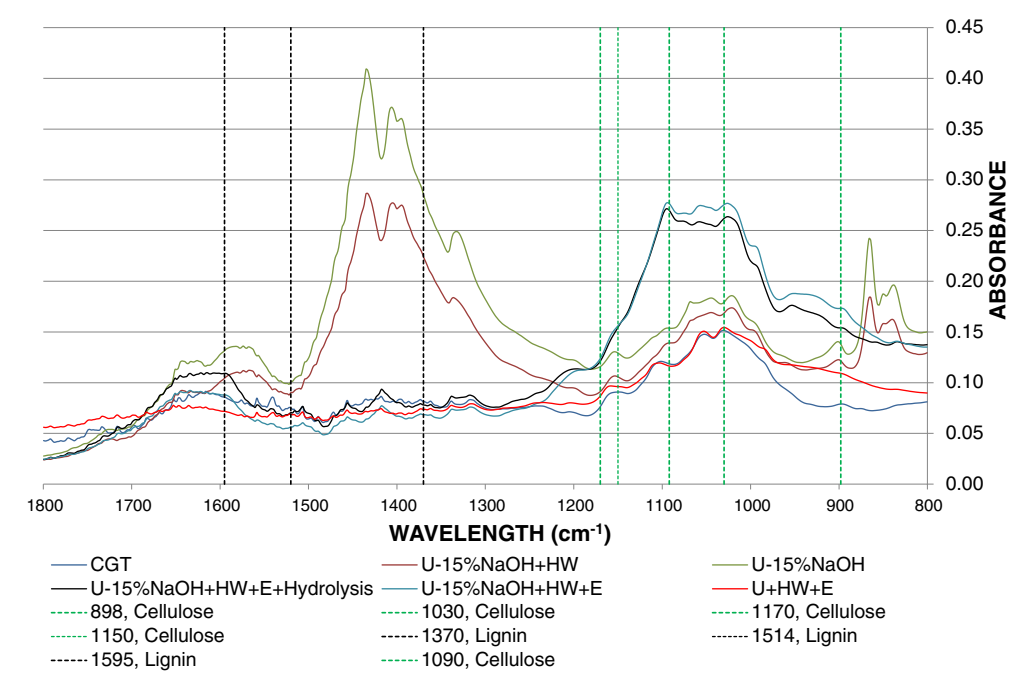

Figure 3 FT-IR spectra for the different steps in the U-NaOH15\%+HW+E pretreatment. 
structure. In addition to the cellulose peak analysis, the cellulose total crystallinity index (TCI) was utilized to evaluate deeper the cellulose structure. The TCI has been used to express the relative amount of crystalline material in cellulose, and it can be defined using the FTIR using the absorbance at A1430/A898 [10]. At the end of the four trials, the TCI decreased in 46\%, 63\%, 66\%, and $67 \%$ for the pretreatments $\mathrm{U}+\mathrm{HW}+\mathrm{E}, \mathrm{U}-\mathrm{NaOH} 5 \%$ $+\mathrm{HW}+\mathrm{E}, \mathrm{U}-\mathrm{NaOH} 10 \%+\mathrm{HW}+\mathrm{E}$, and $\mathrm{U}-\mathrm{NaOH} 15 \%$ $+\mathrm{HW}+\mathrm{E}$, respectively. The reduction in the TCI coincides with the final results observed in the ethanol yield (Figure 2). The decrease in the TCI after alkaline ultrasonication pretreatment was also noticed in the work of Goshadrou et al. [10] over sweet sorghum bagasse, but in sorghum the shrinkage was lower (13\%) than CGT 67\%.

In the fully pretreated biomass, the absorbance in the lignin signals $\left(1,370,1,514\right.$, and $\left.1,595 \mathrm{~cm}^{-1}\right)$ reduced compared with the un-pretreated biomass. The hemicellulose signals $\left(1,240\right.$ and $\left.1,732 \mathrm{~cm}^{-1}\right)$ obtained the greatest variation among the four experiments evaluated. In these peaks, $\mathrm{U}+\mathrm{HW}+\mathrm{E}$ and $\mathrm{U}-\mathrm{NaOH} 15 \%+\mathrm{HW}$ incremented the values; meanwhile, U-NaOH $10 \%+$ $\mathrm{HW}+\mathrm{E}$ and $\mathrm{U}-\mathrm{NaOH} 5 \%+\mathrm{HW}$ reduced the absorbances. These differences can be attributed to the CGT composition and the pretreatment interactions. The increment in the cellulose peak, the diminution in the crystallinity index, and lignin content are some of the reasons why this pretreatment combination produced the greatest cellulose yield and ethanol conversion. The peaks of 898 and $1,030 \mathrm{~cm}^{-1}$ displayed a considerable drop compared with the pretreated biomass; meanwhile, the other peaks did not show any significant change. These differences can be used to follow the hydrolysis reaction of CGT biomass using the FT-IR.

\section{Principal component analysis of the FT-IR spectrum}

This is the first study that use FT-IR spectrum and principal components to analyze the changes produced in the CGT biomass after different pretreatments for ethanol production. The PCA correlated the changes in the absorbance in the FT-IR spectrum and discriminated or grouped the variations in the biomass structure after the different pretreatments. The PCA variables were the spectrum wave numbers in the range 800 to $1,800 \mathrm{~cm}^{-1}$. The pretreatments ( $U, H W$, and $E$ ) and the saccharification process were the variables applied for the grouping. The PCA used 626 observations, 525 variables, and the covariance matrix. The variance explained by the PCA using the two initial principal components (PRIN1, PRIN2) was 91\%, $76 \%$ from PRIN1 and $15 \%$ from PRIN2. PRIN1 and PRIN2 loadings plots (Figure 4) identify which wave numbers were the most important in the variability explained for each principal component $[12,21]$. PRIN1 did not display negative loadings for any of
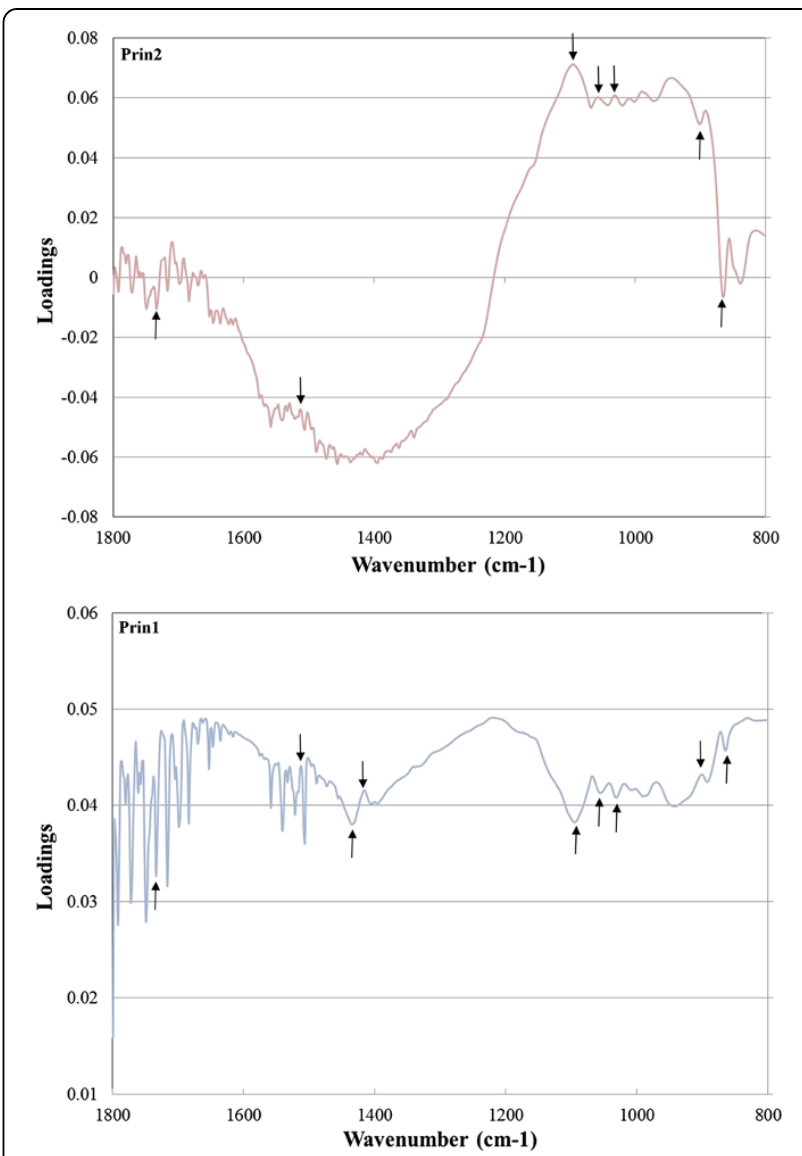

Figure 4 Loading plots of PC1 and PC2 for the CGT FT-IR spectra.

the wave numbers; meanwhile, PRIN2 has negative and positive loadings. In both cases, different minimum and maximum points were possible to identify; the most notable point was at $1,090 \mathrm{~cm}^{-1}$ signal. This signal exhibited high peaks in both principal components, in PRIN1 the signal was the lowest point between 800 and $1,200 \mathrm{~cm}^{-1}$; meanwhile, in PRIN2, it was the highest point in the complete plot. This wave number has been connected with different types of cellulose; this is an indication of the effects of the treatments over the CGT cellulose. Other significant signal was the $864 \mathrm{~cm}^{-1}$; this signal was a minimum in both principal components and corresponds with one of the $\mathrm{NaOH}$ signals found in the FT-IR spectrum (Figure 3). Other signals linked with the $\mathrm{NaOH}$ were detected in the PRIN1 loading plot; these signals correspond to 1,431 and $1,416 \mathrm{~cm}^{-1}$, the first one is a minimum peak, while the second one is a maximum point. These peaks are clearly observed in the FT-IR spectra of the pretreated biomass with alkali ultrasonication and liquid hot water (Figure 3).

The cellulose signals found in the loading plots were the signals at 898 (B-D-cellulose), 1,030, and 1,050 (intense 
polysaccharide), and $1,090 \mathrm{~cm}^{-1}$ (cellulose II and amorphous cellulose) [10,22]. These points were perceived in PRIN1 and PRIN2 loading plots; in PRIN1, 898 and $1,090 \mathrm{~cm}^{-1}$ were minimums, while 1,030 and $1,050 \mathrm{~cm}^{-1}$ were maximums, which is an opposite behavior compared with PRIN2. These signals showed large values in the PRIN2 than PRIN1, which represents the importance of PRIN2 for the cellulose signals explanation. The most significant lignin signal in the loading plots was the signal at $1,514 \mathrm{~cm}^{-1}$ which is related with the aromatic skeletal vibration and $\mathrm{CH}$ deformation. In the same way, the most influential hemicellulose signal in the loading plot was the $1,732 \mathrm{~cm}^{-1}$, this signal was a minimum in both cases and relates the modifications in the esters found in the hemicellulose.

Using the scores plot of the pretreatments (Figure 5), the PCA could group the pretreatments in four clusters, each one associated with the three pretreatments and the saccharified biomass. The groups that displayed the highest separation were the complete pretreated biomass and the saccharified biomass. The clusters were clearer in the treatments $\mathrm{U}-\mathrm{NaOH} 15 \%+\mathrm{HW}+\mathrm{E}$ and $\mathrm{U}-$ $\mathrm{NaOH} 10 \%+\mathrm{HW}+\mathrm{E}$. In these cases, the pretreatments were located sequentially through the PRIN2 axis, this sequence was the same as the experimental order (ultrasonication, hot water, and enzyme). The saccharified biomass spectrum was placed between the HW pretreatment and the enzyme pretreatment. This behavior was also observed in the full FT-IR spectrum where the line of the saccharified biomass descends compared with the $\mathrm{U}-\mathrm{NaOH} 15 \%+\mathrm{HW}+\mathrm{E}$. This reduction is detected in the wave numbers that correspond to the cellulose signals (Figure 3). The scores plot for the $10 \%$ concentration has the saccharification and the full pretreatment clusters closer than the $15 \%$ concentration plot. In the pretreatment $\mathrm{U}-\mathrm{NaOH} 5 \%+\mathrm{HW}+\mathrm{E}$, the ultrasonication and liquid hot water pretreatment groups had similar scores, and the separation between them was not clear (Figure 5). Meanwhile, the separation between the other two clusters improved versus the $10 \%$ plot. The scores plot of the $\mathrm{U}+\mathrm{HW}+\mathrm{E}$ discriminates clearly the sonication pretreatment; nevertheless, the other three groups were not evidently distinguished. In the future, the use of PCA in the CGT's FT-IR spectra can be implemented in the quality control of the biomass for bioethanol production and to predict the behavior of the CGT after different kinds of pretreatments [23].

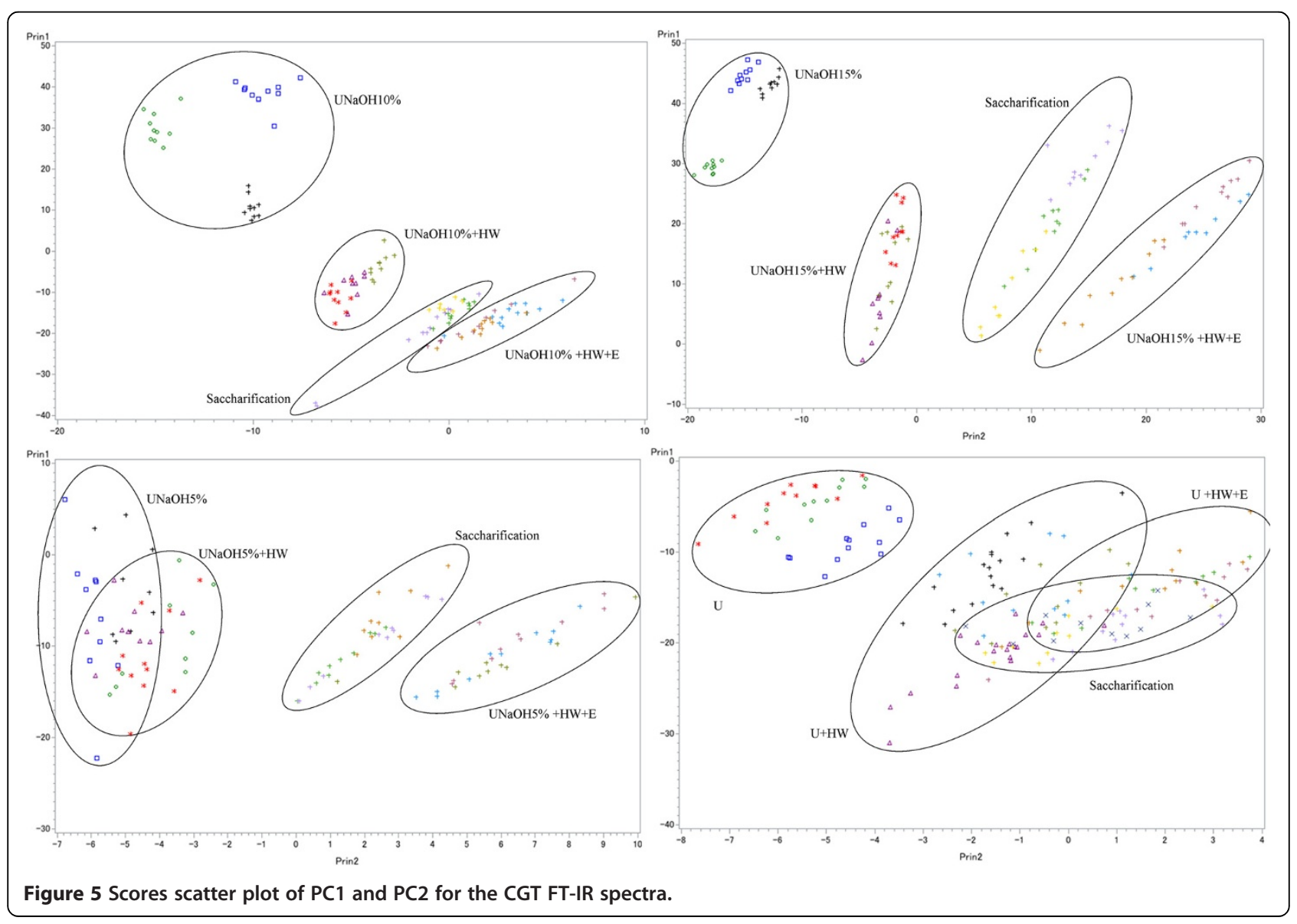




\section{Conclusions}

In this research, the addition of alkali ultrasonication pretreatment to liquid hot water and ligninolytic enzyme pretreatments increased the cellulose conversion in 11\% to $18 \%$ and the ethanol yield in $23 \%$ to $35 \%$ versus the treatment without alkali ultrasonication. From these pretreatments, the $\mathrm{U}-\mathrm{NaOH} 15 \%+\mathrm{HW}+\mathrm{E}$ pretreatment exhibited the highest cellulose conversion (41\%) and ethanol yield (64\%). The use of FT-IR and principal components was effective as a tool to identify the variations in the signal of the cellulose, hemicellulose, and lignin from CGT after the different pretreatments. Additionally, the PCA could separate and identify the CGT biomass from different types of pretreatments and identify the signals with the most significant variation inside the spectra. In the future, this type of discrimination technique can be used in the bioethanol industry for quality control and prediction analysis.

\section{Competing interests}

The authors declare that they have no competing interest.

\section{Authors' contributions}

JP was responsible of experiment's conception and design, acquisition of data, analysis and interpretation of data, and manuscript drafting. SC was responsible of the experiment's conception and design and final manuscript approval. Both authors read and approved the final manuscript.

\section{Acknowledgements}

The Colombian government and the Fulbright Association are acknowledged for the financial support via the granting of FULBRIGHT-COLCIENCIAS for the PHD studies of Jersson Plácido in the USA. Dr. Raghupathy Karthikeyan and the Water Quality Engineering laboratory are acknowledged for their technical and methodological support as well as the BioEnergy Testing and Analysis Laboratory at the Biological and Agricultural Engineering Department and the Texas AgriLife Research of Texas A\&M University for funding this research. GENENCOR International is acknowledged for providing the enzymes employed in the study.

Received: 16 May 2014 Accepted: 22 October 2014

Published online: 05 December 2014

\section{References}

1. Sharma-Shivappa RR, Chen Y (2008) Conversion of cotton wastes to bioenergy and value-added products. T ASABE 51:2239-2246

2. Rogers GM, Poore MH, Paschal JC (2002) Feeding cotton products to cattle. Vet Clin North Am Food Anim Pract 18:267-294

3. Jeoh T, Agblevor FA (2001) Characterization and fermentation of steam exploded cotton gin waste. Biomass Bioenergy 21:109-120

4. Sissine F (2007) Energy Independence and Security Act of 2007: a summary of major provisions $2011 \mathrm{https}$ ://wiki.umn.edu/pub/ESPM3241W/ S09TopicSummaryTeamFourteen/CRS_Report_for_Congress.pdf.

5. Sarkar N, Ghosh SK, Bannerjee S, Aikat K (2012) Bioethanol production from agricultural wastes: an overview. Renew Energy 37:19-27

6. Silverstein RA, Chen Y, Sharma-Shivappa RR, Boyette MD, Osborne J (2007) A comparison of chemical pretreatment methods for improving saccharification of cotton stalks. Bioresour Technol 98:3000-3011

7. Shen J, Agblevor FA (2008) Optimization of enzyme loading and hydrolytic time in the hydrolysis of mixtures of cotton gin waste and recycled paper sludge for the maximum profit rate. Biochem Eng J 41:241-250

8. Plácido J, Imam T, Capareda S (2013) Evaluation of ligninolytic enzymes, ultrasonication and liquid hot water as pretreatments for bioethanol production from cotton gin trash. Bioresour Technol 139:203-208

9. Chaudhary G, Singh LK, Ghosh S (2012) Alkaline pretreatment methods followed by acid hydrolysis of Saccharum spontaneum for bioethanol production. Bioresour Technol 124:111-118
10. Goshadrou A, Karimi K, Taherzadeh MJ (2011) Bioethanol production from sweet sorghum bagasse by Mucor hiemalis. Ind Crop Prod 34:1219-1225

11. Sluiter A, Hames B, Ruiz R, Scarlata C, Sluiter J, Templeton D, Crocker D (2011) Determination of structural carbohydrates and lignin in biomass. Technical report National Renewable Energy Laboratory/TP-51042618:2011:15 http://www.nrel.gov/biomass/pdfs/42618.pdf

12. Popescu M-C, Simionescu BC (2012) Multivariate statistical analysis of mid-infrared spectra for a G1 allyl-terminated carbosilane dendrimer. Spectrochim Acta A Mol Biomol Spectrosc 92:398-405

13. Shi J, Chinn MS, Sharma-Shivappa RR (2008) Microbial pretreatment of cotton stalks by solid state cultivation of Phanerochaete chrysosporium. Bioresour Technol 99:6556-6564

14. Jeihanipour A, Taherzadeh MJ (2009) Ethanol production from cotton-based waste textiles. Bioresour Technol 100:1007-1010

15. Kaur U, Oberoi HS, Bhargav VK, Sharma-Shivappa R, Dhaliwal SS (2012) Ethanol production from alkali- and ozone-treated cotton stalks using thermotolerant Pichia kudriavzevii HOP-1. Ind Crop Prod 37:219-226

16. Chen M, Zhao J, Xia L (2009) Comparison of four different chemical pretreatments of corn stover for enhancing enzymatic digestibility. Biomass Bioenergy 33:1381-1385

17. Velmurugan R, Muthukumar K (2012) Sono-assisted enzymatic saccharification of sugarcane bagasse for bioethanol production. Biochem Eng J 63:1-9

18. Kim I, Han J-I (2012) Optimization of alkaline pretreatment conditions for enhancing glucose yield of rice straw by response surface methodology. Biomass Bioenergy 46:210-217

19. Agblevor F, Batz S, Trumbo J (2003) Composition and ethanol production potential of cotton gin residues. Appl Biochem Biotechnol 105:219-230

20. Duque A, Manzanares P, Ballesteros I, Negro MJ, Oliva JM, Saez F, Ballesteros M (2014) Study of process configuration and catalyst concentration in integrated alkaline extrusion of barley straw for bioethanol production. Fuel 134:448-454

21. Monti F, Dell'Anna R, Sanson A, Fasoli M, Pezzotti M, Zenoni S (2013) A multivariate statistical analysis approach to highlight molecular processes in plant cell walls through ATR FT-IR microspectroscopy: the role of the a-expansion PhEXPA1 in Petunia hybrida. Vib Spectrosc 65:36-43

22. Krasznai DJ, Champagne P, Cunningham MF (2012) Quantitative characterization of lignocellulosic biomass using surrogate mixtures and multivariate techniques. Bioresour Technol 110:652-661

23. Ferreira D, Barros A, Coimbra MA, Delgadillo I (2001) Use of FT-IR spectroscopy to follow the effect of processing in cell wall polysaccharide extracts of a sun-dried pear. Carbohydr Polym 45:175-182

\section{doi:10.1186/s40643-014-0023-7}

Cite this article as: Plácido and Capareda: Analysis of alkali ultrasonication pretreatment in bioethanol production from cotton gin trash using FT-IR spectroscopy and principal component analysis. Bioresources and Bioprocessing 2014 1:23.

\section{Submit your manuscript to a SpringerOpen ${ }^{\circ}$ journal and benefit from:}

- Convenient online submission

- Rigorous peer review

- Immediate publication on acceptance

- Open access: articles freely available online

- High visibility within the field

- Retaining the copyright to your article

Submit your next manuscript at $>$ springeropen.com 